\title{
Application of differential evolution algorithm for parametric optimization of WEDM while machining Nimonic-263 alloy
}

\author{
Sreenivasa Rao M, Venkaiah N
}

\begin{abstract}
Nimonic-263 is a nickel-chromium-cobalt-molybdenum alloy specially meant for use in high temperature and high strength applications. This material is mainly used in gas turbine hot section components. Machining of these high strength materials is a challenging task now a days. Wire cut electrical discharge machining is one of the advanced machining processes and can be used to machine any material, which can electrically conduct, irrespective of its hardness. Selection of process parameters plays a vital role to yield the desired level of performance. An attempt has been made in this work to investigate the behavior of WEDM process while machining Nimonic-263. Response surface methodology has been used for the experimental plan. The influence of process parameters such as pulse on time, pulse off time, peak current and servo voltage on response parameters such as material removal rate and surface roughness has been studied in this work. Mathematical models are developed to predict these responses. Optimal solutions have been identified using RSM. Furthermore, a differential evolution technique has been applied to optimize the WEDM process. The optimal values from RSM have been compared against that of DE technique. The results from DE algorithm were found to be more accurate than that of RSM results. It was also found that pulse on time and peak current are dominating the WEDM process as compared to other process parameters.
\end{abstract}

Keywords-Nimonic-263, EDM, Optimization, RSM, Differential Evolution

Sreenivasa Rao M

Mechanical Engineering Department

National Institute of Technology-Warangal, India

Dr. Venkaiah N

Mechanical Engineering Department

National Institute of Technology-Warangal, India

\section{Introduction}

WEDM is one of the advanced machining processes, in this process the material is eroded by a series of discrete electrical discharges between the workpiece and the tool. These discharges cause sparks and result in high temperatures instantaneously, up to about $10000^{\circ} \mathrm{C}$. These temperatures are huge enough to melt and vaporize the workpiece metal and the eroded debris cools down swiftly in working liquid and flushed away. WEDM does not make direct contact between wire and workpiece where it can eliminate mechanical stresses chatter and vibration problems during machining. Materials of any hardness can be cut as long as the material can conduct electricity [1]. Taguchi experimental design [2-5] has been used by researchers to model the WEDM process and there by optimize the performance. Whereas some researchers used these developed mathematical models for further optimization using techniques like GA [6]. RSM technique was used by some researchers to model the WEDM process as well to optimize the responses of the process [7-8]. The optimization techniques like artificial bee colony $(\mathrm{ABC})$, back-propagated neural network (BPNN) integrated GA were used by some researchers [9-10] for further optimization of WEDM process. Data mining was used by Kuriakose et al. [11] to model the WEDM process. Tarng et al.[12] used a feed forward neural network to model the WEDM process and then SA was applied to optimize the $\mathrm{NN}$ model.

\section{Experimental Setup}

Nimonic-263 material has been machined using WEDM of Electronica (India) make. The chemical compositions of Nimonic-263 in percentage are C: 0.043 , Co: 19.5 , Mo: 5.6, Mn: 0.43, Si:0.04, S:0.005, P: 0.005, Cr: 20, Fe: 0.25, Ti: 2.2, Al: $0.48, \mathrm{Cu}: 0.002, \mathrm{O}: 0.0022, \mathrm{~N}: 0.0031$ and balance is Nickel. The size of the workpiece material is $120 \mathrm{~mm} \times 110 \mathrm{~mm} \times 18.5 \mathrm{~mm}$ and $10 \mathrm{~mm}$ diameter holes were produced on it. Process parameters considered in the present work are pulse on time, pulse off time, peak current and servo voltage. After conducting trial experiments, levels of each process parameter has been fixed as pulse-on time $\left(\mathrm{T}_{\text {on }}\right)$ : 105$125 \mu \mathrm{s}$, pulse-off time $\left(\mathrm{T}_{\text {off }}\right): 50-60 \mu \mathrm{s}$, peak current $\left(\mathrm{I}_{\mathrm{p}}\right): 10-12$ A and servo voltage $\left(S_{v}\right)$ : $40-60 \mathrm{~V}$. Material removal rate and surface roughness have been considered as performance measures and aimed to optimize these responses with RSM. Material removal rate was calculated using the equation (1). Coordinate Measuring Machine (CMM) was used to measure the diameters. 


$$
M R R=\frac{\pi\left(D^{2}-d^{2}\right) h}{4 T} \mathrm{~mm}^{3} / \mathrm{min}
$$

where, $D=$ diameter of the hole $(\mathrm{mm}), d=$ diameter of the blank (mm), $h=$ height of the work piece $(\mathrm{mm})$ and $T=$ Time taken for machining (min). MarSurf M-400, a surface roughness measuring instrument was used to measure the surface roughness of the machined surface.

Response surface methodology (RSM) has been applied for experimental plan and also to model the responses of MRR and SR. As per RSM, 26 experiments were conducted. ANOVA has been used to estimate the significance of each parameter and its contribution. The response models are used to predict the response values and also for further optimization. Differential evolution (DE) technique has been applied in this paper to optimize MRR and SR and these results are compared with RSM results.

\section{Differential evolution algorithm and its methodology}

Differential evolution algorithm is a stochastic, population based algorithm, introduced by Storn and Price in 1996. The steps in implementation of DE are described [13] as follows.

Initialization: The initial population is generated randomly within the feasible variable ranges. In any evolutionary algorithm, the initial population is generated for each control variable using the following equation (2). The value of $i^{\text {th }}$ particle's $j^{\text {th }}$ variable is given by:

$$
x_{i, j}=x_{j}^{\text {min }}+\text { rand }(0,1)\left(x_{j}^{\max }-x_{j}^{\min }\right)
$$

Where $x_{j}^{\max }$ and $x_{j}^{\min }$ are the upper and lower bunds of $j^{\text {th }}$ variable respectively.

Mutation: At every stage of generation, a donar vector $d_{i}(t)$ is created. Three different members $x_{r 1}, x_{r 2}$ and $x_{r 3}$ are chosen randomly from the current population and not coinciding with the current member $x_{i}$. Therefore, the $j^{\text {th }}$ component of $d_{i}(t)$ can be expressed as,

$$
d_{i, j}(t+1)=x_{r 1 j}(t)+F\left(x_{r 2 j}(t)-x_{r 3 j}(t)\right)
$$

This creates the donor vector $v_{i}(t)$. typical value of $F$ is in the range of 0.4-1.0.

Crossover: To increase the diversity of the population, crossover operator is carried out in which the donor vector exchanges its components with those of the current member $x_{i}$ $(t)$. The crossover is performed on all the variables as far as the randomly picked number, between 0 and 1 , is within the $\mathrm{CR}$ value.

$$
u_{i, j}(t)=\left\{\begin{array}{l}
d_{i, j}(t) \text { if rand }(0,1)<\mathrm{CR} \\
x_{i, j}(\mathrm{t}) \text { else }
\end{array}\right.
$$

$u_{i, j}(t)$ represents the child that will compare with the parent $x_{i, j}(t)$.

Selection: To keep the population size constant over subsequent generations, the selection process is carried out to determine which one of the child and the parent will survive in the next generation, i.e., at time $t=t+1$. DE actually involves the survival of the fittest principle in its selection process. The selection process can be expressed as,

$$
x_{i}(\mathrm{t}+1)= \begin{cases}u_{i}(\mathrm{t}) & \text { if } f\left(\mathrm{u}_{i}(t)\right) \leq f\left(\mathrm{x}_{i}(t)\right) \\ x_{i}(\mathrm{t}) & \text { if } f\left(\mathrm{x}_{i}(t)\right)<f\left(\mathrm{u}_{i}(t)\right)\end{cases}
$$

Where, function $f()$ is the function to be minimized in this case. So, if the child yields a better value of the fitness function, it replaces its parent in the next generation; otherwise, the parent is retained in the population. Hence the population either gets better in terms of the fitness function or remains constant but never deteriorates. This procedure will be continued till the maximum number of generations is reached.

\section{Results and analysis}

ANOVA has been applied on the experimental results for both MRR and SR. It has been observed from the ANOVA results of MRR, that $T_{o n}, I_{p}$, and interaction of $T_{\text {on }}$ and $I_{p}$ are significant model terms and are shown in the Fig. 1(a), (b) and (c). Higher the pulse-on time, higher will be the energy applied there by generating more amount of heat energy during this period and it leads to higher MRR. Peak current is the amount of power used in discharge machining. Higher the peak current, higher will be the energy applied at machining and there by increasing the MRR. The mathematical model generated for MRR was given in equation (6), in the coded form. From the ANOVA, the R-Square, adjusted R-square and predicted R-square values were found to be $96.2 \%, 94 \%$ and $90 \%$ respectively for the model.

$$
\begin{aligned}
M R R= & 0.42+0.50 A-0.068 B+0.88 C \\
& -0.11 D+0.60 \mathrm{AC}-0.089 \mathrm{BC} \\
& -0.12 \mathrm{CD}-0.062 \mathrm{~A}^{2}+0.95 C^{2}
\end{aligned}
$$

From the ANOVA Results of SR, it has been observed that $\mathrm{T}_{\mathrm{on}}, \mathrm{I}_{\mathrm{p}}, \mathrm{S}_{\mathrm{v}}$ and interaction effects $\mathrm{T}_{\mathrm{on}}$ and $\mathrm{I}_{\mathrm{p}}, \mathrm{T}_{\text {on }}{ }^{2}$ and $\mathrm{I}_{\mathrm{p}}{ }^{2}$ are significant model terms, and are shown in the Fig. 2(a), (b), (c) and (d). When the pulse-ontime increases, the number of discharges also increases. It leads to more heat energy there by increasing the machining rate and decresing the surface finish. Higher the peak current, higher will be the energy applied and it leads to higher maching rate and high surface roughness. At higher values of servo voltage, the gap between workpiece and wire becomes wider and it decreases the number of sparks, stabilizes electric discharge yielding better surface finish 
Proc. of the Intl. Conf. on Advances in Civil, Structural and Mechanical Engineering - ACSM 2015.

Copyright (C) Institute of Research Engineers and Doctors, USA .All rights reserved.

ISBN: 978-1-63248-039-2 doi: 10.15224/ 978-1-63248-039-2-82
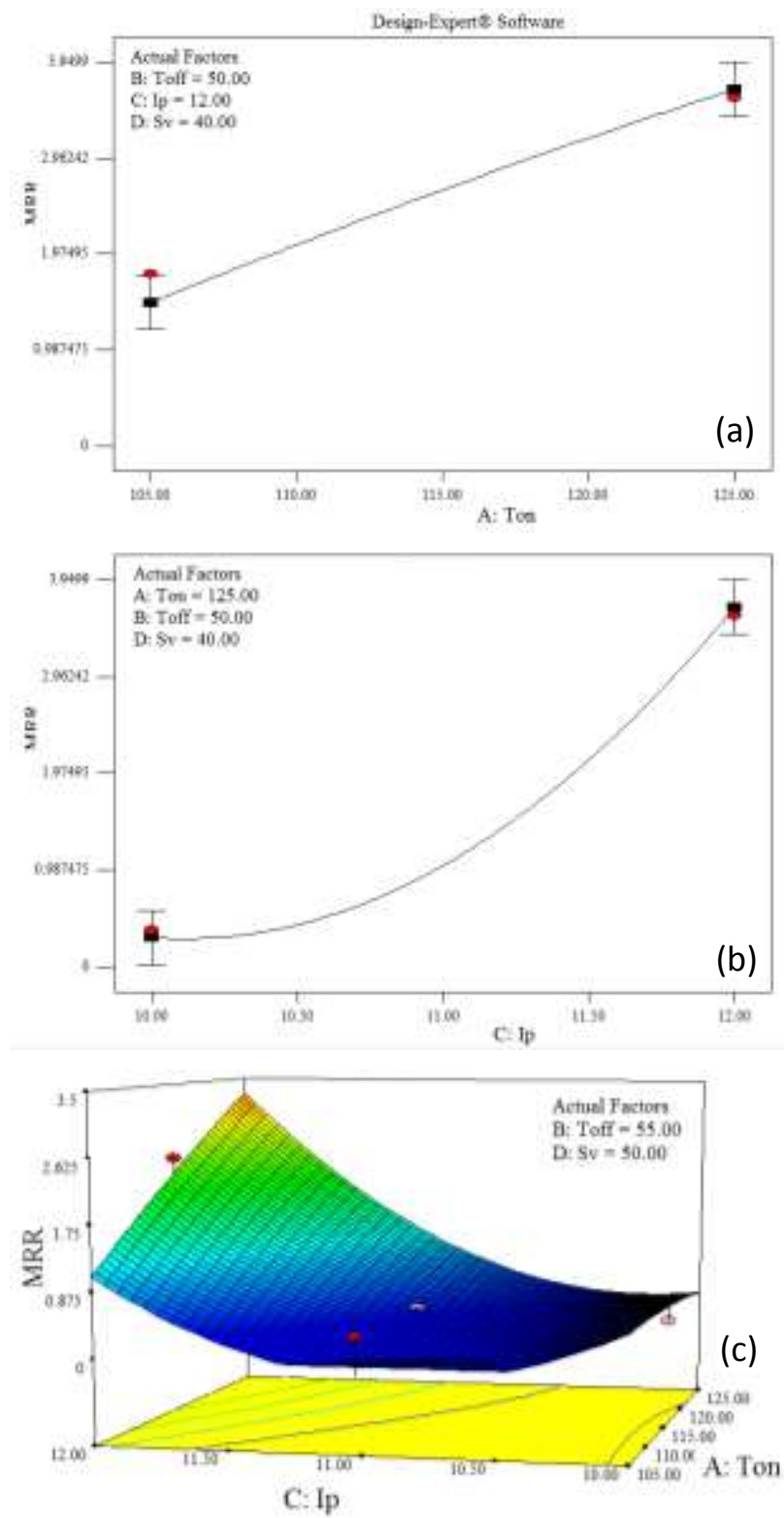

Figure 1. (a) Effect of $T_{\text {on }}$ on MRR, (b) Effect of $I_{p}$ on MRR, (c) Effect of $\mathrm{T}_{\mathrm{on}}$ and $\mathrm{I}_{\mathrm{p}}$ on MRR

The mathematical model generated for SR is given in equation (7) in the coded form. From the ANOVA, the RSquare, adjusted R-square and predicted R-square values were found to be $92 \%, 84.22 \%$ and $72 \%$ respectively for the model. The predicted R-Square of $72 \%$ is in reasonable agreement with the adjusted R-Square of 0.8422 .

$$
\begin{aligned}
S R= & 0.55+0.16 A+0.069 B+0.27 C-0.14 D \\
& +0.059 A B+0.40 A C+0.082 A D \\
& -0.005437 B C+0.028 C D+0.27 A^{2}+0.30 C^{2}
\end{aligned}
$$

The optimal values for MRR and SR were found to be $3.59856 \mathrm{~mm}^{3} / \mathrm{min}$ and $0.363162 \mu \mathrm{m}$ using RSM respectively. These results along with their optimal parameters are given in Table 1. Similarly the optimal values found from DE for MRR and SR were $3.6713 \mathrm{~mm}^{3} / \mathrm{min}$ and $0.2618 \mu \mathrm{m}$ respectively.
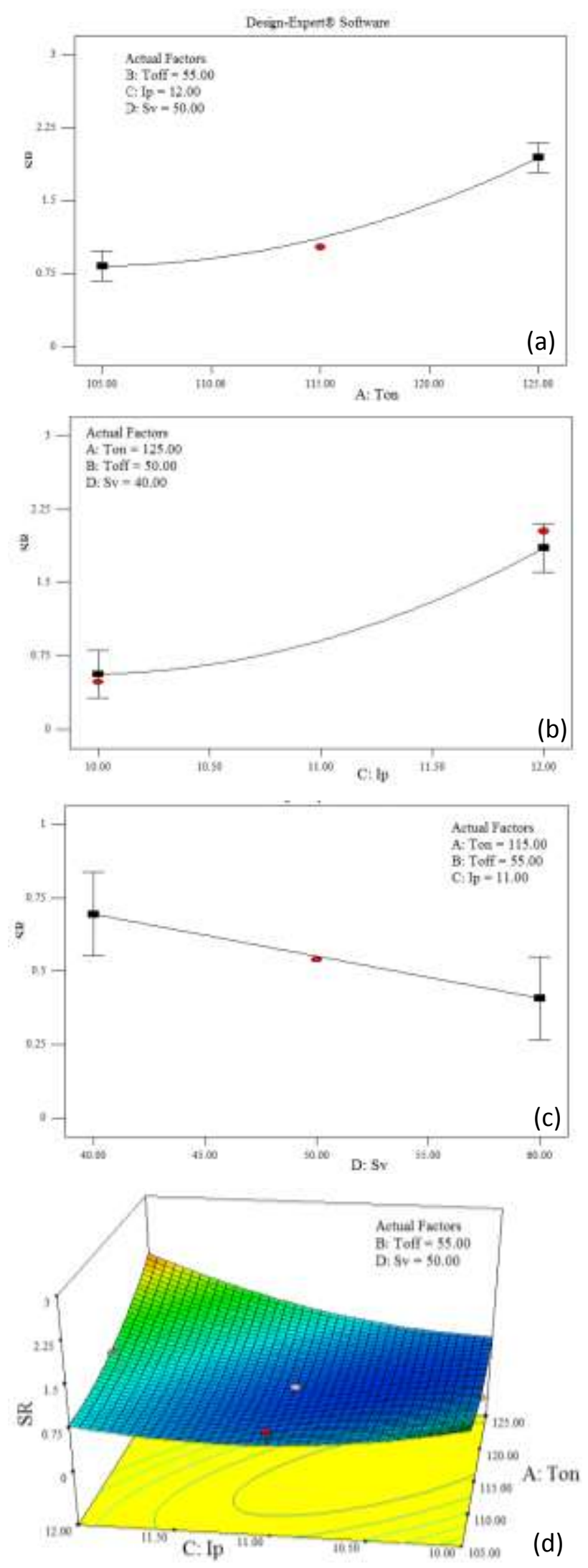

Figure 2. (a) Effect of $\mathrm{T}_{\mathrm{on}}$ on $\mathrm{SR}$, (b) Effect of $\mathrm{I}_{\mathrm{p}}$ on $\mathrm{SR}$, (c) Effect of $S_{v}$ on SR, (d) Effect of $T_{\text {on }}$ and $I_{p}$ on SR 
Proc. of the Intl. Conf. on Advances in Civil, Structural and Mechanical Engineering - ACSM 2015.

Copyright $($ Institute of Research Engineers and Doctors, USA .All rights reserved.

ISBN: 978-1-63248-039-2 doi: 10.15224/ 978-1-63248-039-2-82

TABLE 1. The Optimal results from RSM and DE

\begin{tabular}{|c|c|c|c|c|}
\hline \multirow{2}{*}{ Response } & \multicolumn{2}{|c|}{$\operatorname{MRR}\left(\mathrm{mm}^{3} / \mathrm{min}\right)$} & \multicolumn{2}{|c|}{ SR $(\mu \mathrm{m})$} \\
\hline & $\begin{array}{l}\text { Optimal } \\
\text { value }\end{array}$ & $\begin{array}{l}\text { Optimal } \\
\text { parameters }\end{array}$ & $\begin{array}{l}\text { Optimal } \\
\text { value }\end{array}$ & $\begin{array}{l}\text { Optimal } \\
\text { parameters }\end{array}$ \\
\hline RSM & 3.59856 & $\begin{array}{l}\mathrm{T}_{\text {on }}: 125 \mu \mathrm{s}, \\
\mathrm{T}_{\text {off }}: 52.14 \mu \mathrm{s}, \\
\mathrm{Ip}: 12 \mathrm{~A}, \\
\mathrm{~Sv}: 42 \mathrm{~V}\end{array}$ & 0.36316 & $\begin{array}{l}\mathrm{T}_{\mathrm{on}}: 119 \mu \mathrm{s}, \\
\mathrm{T}_{\text {off }}: 51 \mu \mathrm{s}, \\
\mathrm{Ip}: 10 \mathrm{~A}, \\
\mathrm{~Sv}: 56 \mathrm{~V}\end{array}$ \\
\hline $\mathrm{DE}$ & 3.6713 & $\begin{array}{l}\mathrm{T}_{\text {on }}: 125 \mu \mathrm{s}, \\
\mathrm{T}_{\text {off }}: 50 \mu \mathrm{s}, \\
\mathrm{Ip}: 12 \mathrm{~A}, \\
\mathrm{~Sv}: 40 \mathrm{~V}\end{array}$ & 0.2618 & $\begin{array}{l}\mathrm{T}_{\mathrm{on}}: 116 \mu \mathrm{s}, \\
\mathrm{T}_{\text {off: }}: 50 \mu \mathrm{s}, \\
\text { Ip: } 10 \mathrm{~A}, \\
\mathrm{~Sv}: 60 \mathrm{~V}\end{array}$ \\
\hline
\end{tabular}

Confirmation tests have been conducted to check the effectiveness of DE for both MRR and SR, and the results are presented in Table 2.

TABLE 2. Confirmation test results

\begin{tabular}{|c|c|c|}
\hline Response & $\begin{array}{c}\text { MRR }\left(\mathbf{m m}^{3} / \mathbf{m i n}\right) \\
\text { Ton:125 } \mathbf{\mu s}, \text { Toff:50 } \boldsymbol{\mu s}, \\
\text { Ip:12 A, Sv:40 V }\end{array}$ & $\begin{array}{c}\text { SR }(\boldsymbol{\mu m}) \\
\text { Ton:116 } \boldsymbol{\mu s} \text {, Toff:50 } \boldsymbol{\mu s}, \\
\text { Ip:10 A, Sv:60 V V }\end{array}$ \\
\hline $\begin{array}{c}\text { Predicted value } \\
\text { from DE }\end{array}$ & 3.6713 & 0.2618 \\
\hline $\begin{array}{c}\text { Experimental } \\
\text { Value }\end{array}$ & 3.614 & 0.282 \\
\hline $\begin{array}{c}\text { Deviation in } \\
\text { percentage }\end{array}$ & 1.6 & 7 \\
\hline
\end{tabular}

\section{Conclusions}

Response surface methodology has been used in the present study to model WEDM performance measures such as material removal rate and surface roughness. Pulse on time, pulse off time, peak current and servo voltage have been considered as input parameters. The significance of process parameters have been identified by applying ANOVA analysis for both MRR and SR. For MRR it was found from the ANOVA results that, pulse on time, peak current and interaction effect of pulse on time and peak current are more influencing than other model terms. Whereas for SR, it was found that pulse on time, peak current, servo voltage and interaction effect of pulse on time and peak current are significant. In the present research an attempt has been made to apply DE to optimize the responses such as MRR and SR. The optimal response values from RSM and DE are compared. It is found that, the results of DE are better than that of RSM. Due to wide range of applications for Nimonic-263, the machining data generated in this work using WEDM will be useful to the industry.

\section{Acknowledgment}

Authors would like to thank DST-SERB of India for providing financial assistance to carry out this work through project No.SR/FTP/ETA-10/2012.

\section{References}

[1]. Shajan Kuriakose and M.S. Shunmugam, "Characteristics of wire-electro discharge machined Ti6Al4V surface", Materials Letters, vol. 58, pp. 2231-2237, 2004.

[2]. Y.S.Liao, J.T. Huang and H.C. Su, "A study on the machining-parameters optimization of wire electrical dischargs machining", Journal of Materis Processing Technology, vol.71, pp. 487- 493, 1997.

[3]. R. Konda, K.P. Rajurkar, R.R. Bishu, A. Guha and M. Parson, "Design of experiments to study and optimize process performance", International Journal of Quality \& Reliability Management, vol. 16, pp. 56-71, 1999.

[4]. A. Manna and B. Bhattacharyya, "Taguchi and Gauss elimination method: A dual response approach for parametric optimization of $\mathrm{CNC}$ wire cut $\mathrm{EDM}$ of PRAlSiCMMC", International Journal of Advanced Manufacturing Technology, vol. 28 pp. 67-75, 2006.

[5]. S.R. Nithin Aravind, S. Sowjanya and K.P. Yuvaraj, "Optimization of metal removal rate and surface roughness on Wire EDM using Taguchi method", IEEE International Conference on Advances in Engineering Science and Management(ICAESM-2012), pp.155-159, March $30-31,2012$.

[6]. S S Mahapatra \& Amar Patnaik, "Optimization of wire electrical discharge machining (WEDM) process parameters using genetic algorithm", Indian journal of Engineering \& Materials Science, vol. 13, pp. 494-502, 2006.

[7]. Neeraj Sharma, Rajesh Khanna, Rahul Dev Gupta and Renu Sharma, "Modeling and multiresponse optimization on WEDM for HSLA by RSM", International Journal of Advanced Manufacturing Technology, vol. 67, pp. 22692281, 2013.

[8]. Pragya Shandilya, P.K. Jain and N.K. Jain, "Parametric optimization during wire electrical discharge machining using response surface methodology", Procedia Engineering, vol. 38, pp. 2371 - 2377, 2012.

[9]. R.V Rao, P.J. Pawar, "Modelling and optimization of process parameters of wire electrical discharge machining", Proceedings of the Institution of Mechanical Engineers, Part B: Journal of Engineering Manufacture vol. 223, pp. 1431-1440, 2009. 
[10]. Guojun Zhang, Zhen Zhang, Jianwen Guo, Wuyi Ming, Mingzhen Li, and Yu Huang, "Modeling and Optimization of Medium-Speed WEDM Process Parameters for Machining SKD11", Materials and Manufacturing Processes, vol. 28, pp. 1124-1132, 2013.

[11]. Shajan Kuriokose, Kamal Mohan, M.S. Shunmugam, "Data mining applied to wire-EDM process", Journal of Materials Processing Technology, vol. 142, pp. 182-189, 2003.

[12]. Y.S. Tarng, S.C. Ma and L.K. Chung, "Determination of optimal cutting parameters in wire electrical discharge machining", International Journal of Machine Tools \& Manufacture, vol. 35, pp. 6931701, 1995.

[13]. A A Abou El Ela, M A Abido and S R Spea, "Optimal power flow using differential evolution algorithm", Electric Power Systems Research, vol. 80, pp. 878-885. 